\title{
Evaluating Human Resource Capacity for Crop Breeding in National Programs in Africa and South and Southeast Asia
}

\author{
Ndeye Ndack Diop, Fredrick Okono, Jean-Marcel Ribaut \\ CGIAR Generation Challenge Programme, Texcoco, México \\ Email: nn.diop@cgiar.org
}

Received August 29 ${ }^{\text {th }}$, 2013; revised September 29 $9^{\text {th }}$, 2013; accepted October $6^{\text {th }}, 2013$

\begin{abstract}
Copyright (C 2013 Ndeye Ndack Diop et al. This is an open access article distributed under the Creative Commons Attribution License, which permits unrestricted use, distribution, and reproduction in any medium, provided the original work is properly cited.
\end{abstract}

\begin{abstract}
Plant breeders must keep abreast of the rapid evolution of new technologies, and also implement information management strategies that efficaciously handle the ever growing amount of data required for efficient integrated breeding. Updated training for breeders is critical to build relevant human resource capacity, particularly in developing countries whose breeding programs suffer a lack of staff with diverse expertise. The CGIAR Generation Challenge Programme is leading such a capacity-building initiative. A survey was conducted among course nominees to establish a baseline of breeder level of education, knowledge and skills in analyzing data and their involvement in molecular breeding programs. The breeders were mainly from three regions: West and Central Africa, East and Southern Africa, and South and Southeast Asia, and also included a few participants from North Africa. Many of the breeders from all the regions held or were working towards a $\mathrm{PhD}$. Gender balance was low, principally in West and Central Africa, where less than $15 \%$ of the breeders were women. Between $57 \%$ and $73 \%$ of the breeders surveyed in the different regions were involved in molecular breeding projects at regional or international level. The Use of multiple software tools by individual breeders for data analysis was low for breeders from all the regions, with most using 1 - 3 packages. A lack of high data-analysis capacity will be a problem in an era where integration of genomics and phenotypic data in breeding programs is essential to efficiently deliver improved cultivars.
\end{abstract}

Keywords: Training; Breeders; Developing Countries; Molecular Breeding

\section{Introduction}

Integrated breeding approaches take advantage of all possible tools and methodologies (from simple phenotyping to complex genomic selection) to most efficiently achieved crop selection. An overall decrease in the number of plant breeders and a lack of the new skills required to conduct modern integrated breeding are real challenges for crop improvement and food security worldwide, but particularly in developing countries. In these countries the challenge is even greater because staff reductions require a breeder to compensate by mastering a diverse range of skills and competencies. This shortage of staff is the result of a freeze in recruitment in most breeding institutions in Sub-Sahara Africa since the 1980s, after the implementation of the structural adjustment policies of the International Monetary Fund (IMF) and the World Bank (WB) that reduced public investment in agricultural research. This further diminished the human resource capacity of breeding programs that already had too few trained breeders (Guimaraes et al., 2006), exacerbated by limited funding to access modern tools and a general lack of support from governments. This situation makes most breeding programs in developing countries dependent on donors with their particular research objectives, creating an increased demand for short-term impact which is quite a challenge in plant breeding (Ribaut et al., 2008). In developed countries on the other hand, the overall number of plant breeders in the private and public sectors has decreased concomitantly with decreased numbers of students trained because breeding has been in increasing competition with other disciplines such as genomics and bioinformatics. In the public sector, this has resulted in the replacement of retiring breeders by scientists involved in more basic genetic studies (Gepts \& Hancock, 2006). As a result, the seed industry has become the main employer of plant breeders to meet the needs of cultivar development. In the USA, these breeders represent about $70 \%$ of all plant breeders because by nature the seed business greatly depends on producing competitive new cultivars (Bliss, 2007). However, this notion of decreasing numbers of breeders needs to be considered in the context that a modern breeding team is composed of people with different expertise. Huge progress has been made in field management and analytical tools, so selection power in terms of genetic gained efficiency and the number of plots per crop cycle has increased significantly over the last decade. Such an optimal breeding team is likely to be found in the private sector and centers of the CGIAR (formally the Consultative Group on International Agricultural Research) and in Advanced Research Institutions (ARIs).

In developing countries, breeding teams will most likely be composed of the main breeder and several technicians for whom the numbers will vary depending on availability of resources. However, the breeders still have to perform efficient conventional selection which is the basis of any breeding activ- 
ity - that includes a good understanding of field experimental designs, phenotyping screening methodologies and statisticsbut also have some understanding of how to integrate new genomics approaches in their breeding program to deliver cultivars most efficiently. The breeding and biotechnology capacity in developing countries was assessed through a survey (Guimaraes et al., 2006; Guimarães et al., 2007) and updated information is available in the online database of the Global Partnership Initiative for Plant Breeding Capacity Building (GIPB) "Plant Breeding and Related Biotechnology Capacity Assessments" at

http://gipb.fao.org/Web-FAO-PBBC/index.cfm?where=02 (verified 27 Aug. 2013). In this reported survey the use of biotechnologies in breeding was only just the beginning, with different levels of capacity among the 12 countries surveyed, of which three in fact had no biotechnologists in 2001. Updated data from the GIPB database showed that the number of biotechnologists had increased in most countries with only a limited number of countries that did not report any biotechnologists.

The limited skills of breeding teams in developing countries can still be a bottleneck in the integration of molecular markers into plant breeding strategies-now recognized as an effective way to enhance crop improvement in the 21st century (Moose \& Mumm, 2008). Often described as "molecular breeding" (MB), this usually includes marker-assisted selection (MAS), marker-assisted backcrossing (MABC), marker-assisted recurrent selection (MARS) and genome wide selection (GWS) (Ribaut et al., 2010). MB is widely used for crop improvement and cultivar development in developed countries, especially in breeding programs in private-sector seed companies. Gene discovery and knowledge of marker-trait associations have even greater potential for developing new cultivars that can face challenges of biotic and abiotic stresses while maintaining high yields. Understanding the genetic basis of complex traits and the pyramiding of favorable alleles for native traits will likely be the basis of new opportunities for crop improvement (Bliss, 2007; Varshney et al., 2012) and the next "green revolution".

One constraint to the use of MB in developing countries has been limited genomics resources for most tropical crops, including legumes, dry land cereals and clonal crops. However, this constraint is being overcome by research investment in developing genomic resources for crops often considered "orphans” (Raju et al., 2010; Varshney et al., 2010; Gautami et al., 2012). Most staple crops in developing countries now have adequate genomic resources for meaningful genetic studies and most MB applications (Ribaut et al., 2010). The use of singlenucleotide polymorphism (SNPs) markers in high-throughput genotyping systems has contributed to a significant drop in prices per data point (Delannay et al., 2012). While poor infrastructure and lack of trained personnel have previously limited adoption of $\mathrm{MB}$, the falling prices for genotyping have made outsourcing such services cost effective and reduced the need to perform genotyping in expensive individual in-house laboratories. This has increased access to genotypic data for a large number of scientists, regardless of their background in molecular studies and laboratory experience. The challenge has hence shifted from data acquisition to equipping breeders with sufficient knowledge and tools to analyze important data from the field and laboratories for use in cultivar development.

With these developments, today's breeders face the challenge of understanding how to take advantage of ever-expanding new knowledge, spanning from marker-trait associations, quantitative trait loci (QTL) mapping, genomics and gene discovery to its use in breeding programs to increase genetic gain-all while delivering cultivars to farmers in a timely manner. Updated training on newly-developed technologies and their application in breeding is required to allow practicing breeders to take full advantage of this data revolution. New generations of breeders coming out of colleges similarly require the essential knowledge, skills and practical exposure in these fields to prepare themselves for the challenges they will face very early in their careers (Gepts \& Hancock, 2006; Bliss, 2007; Repinski et al., 2011). In addition to their breeding expertise they require working knowledge of experimental design, advanced statistical methods, phenotyping methodologies and genotype-byenvironment $(G \times E)$ interactions (Morris et al., 2006; Delannay et al., 2012). This is even more challenging in developing countries because the lack of staff and resources requires them to cover a wider range of activities. Fortunately, with the outsourced laboratories, breeders do not have to add laboratory skills to their already long list of requisite expertise. They only need to give breeding value to results they obtain from outsourced service providers.

To facilitate adoption of MB in the public sector, and especially in developing countries, the GCIAR Generation Challenge Programme (GCP, www.generationcp.org; verified 27 Aug. 2013) is leading the Integrated Breeding Platform initiative (IBP, www.integratedbreeding.net; verified 27 Aug. 2013) (Delannay et al., 2012; Ribaut et al., 2013). This will enable accelerated variety development using marker technologiesfrom simple gene or transgene introgression to gene pyramiding and complex MARS and GWS projects. The initiative has three main components: the web portal—a gateway for the tools, manuals, breeding materials, crop databases and breeding services; the Integrated Breeding Workflow System (IBWS) - an integrated software system for managing breeding logistics, data, analyses, simulation and decision making through a user friendly interface; and a brokerage of molecular marker laboratory services and capacity development activities (Delannay et al., 2012).

The program of plant breeding capacity-building reported here is an integral component of the IBP initiative, the goal being to train 180 scientists working on the nine GCP target crops (bean, cassava, chickpea, cowpea, groundnut, maize, rice, sorghum and wheat) plus pigeonpea and soybean. These are important crops in the three main target regions: West and Central Africa (WCA), East and Southern Africa (ESA) and South and Southeast Asia (SSEA). The training program will provide access to modern tools to design and more efficiently manage breeding experiments and better analyze genotypic and phenoltypic data generated by their projects. The program will also help to prepare breeders to meet challenges of managing information and data central to $\mathrm{MB}$, as this takes root and becomes an integral part of crop improvement programs in the target countries. Participants will acquire a comprehensive understanding of activities right from the initiation of an MB project, through identification of target traits and markers correlated to the breeding objective, to utilization of molecular markers. Ultimately, they will gain the expertise needed to use molecular markers efficiently and when needed in their programs.

The objective of this paper is to provide information on breeding capacity in the public sector mainly in Sub-Saharan 
Africa (SSA) and South and South-East Asia (SSEA). In addition to the information obtained from the GIPB database, this paper reports on the level of education, knowledge and expertise in data analysis and $\mathrm{MB}$ application within their breeding programs by a broad group of 367 scientists who applied to attend the Integrated Breeding Multi-Year Course (IB-MYC).

\section{Materials and Methods}

\section{Description of the Training}

The IB-MYC technical training program was started to train a purpose-selected group of potential IBP users over a threeyear period (2012-2014 for the first cohort). This consisted of two weeks of face-to-face training per year, imparting progressively more complex skills and providing post-training evaluation and support to help overcome implementation challenges and ensure long-term and sustainable adoption. The IB-MYC follows a modular approach based on the sequential steps of an integrated breeding project. The informatics tools and services of the IBP project provide and support practical elements of the course, and the trainees are an integral part of the Platform development process by providing real-life field testing and feedback. Hence, at the end of the three-year period, the trainees are expected to have a high proficiency in both conventional and molecular breeding methodologies in general, as well as use of the IBP informatics tools and services developed and customized to support MB in their particular environments and circumstances. Simultaneously, trainees will establish communities of practice (CoPs) that provide peer-to-peer technical support under the oversight of the trainers, incorporating mentoring, exchange of information and breeding materials, and collective problem-solving. Establishing CoPs among student breeders for evaluating and reflecting on their experience in plant breeding is recommended by Repinski et al. (2011).

The IB-MYC (www.integratedbreeding.net/ib-multi-year-course, verified 27 Aug. 2013) training covers three core areas: molecular breeding (MB), data management (DM) and data analysis and statistics (DAS). The MB section focuses on imparting knowledge of breeding methodologies that use molecular markers. Instruction includes why, how and when to use the different methodologies. The DM module examines how breeders can efficiently access relevant information generated by themselves and other scientists. It addresses management of germplasm, population, phenotypic and genotypic data, and on the use of crop information databases in breeding programs. The DAS module covers analysis of phenotypic data generated from single and multiple environments including $G \times E$ interactions, estimation of genetic variance parameters, and analysis of genotypic data and detection of QTLs in single and multiple environment setting. It also covers experimental design, and how to select one based on the research objectives.

\section{Nomination Procedures}

A call was sent in early 2012 to all GCP collaborators requesting nomination of candidates working on GCP's nine target crops (bean, cassava, chickpea, cowpea, groundnut, maize, rice, sorghum and wheat) and two other important crops, pigeonpea and soybean, a request for nominations was also sent to other networks such as the Africa Rice Breeding Task Force, the African Centre for Crop Improvement (ACCI), the West African Centre for Crop Improvement (WACCI), the GIPB and
Rothamsted International African Fellowship Programme (AFP) Alumni in order to reach outside the extended GCP community. The list of nominees was shared with regional organizations in WCA (CORAF/WECARD-Conseil ouest et centre africain pour la recherche et le développement agricoles/West and Central African Council for Agricultural Research and Development) and ESA (ASARECA-Association for Strengthening Agricultural Research in Eastern and Central Africa) to ensure inclusion of their key partners.

The primary target of the program was breeders and crop improvement scientists from developing countries in SSA and SSEA that were carrying out research activities and research data analysis. These included senior, middle-level and upcoming breeders/scientists. Nominees who held an MSc degree in plant breeding, plant genetics, biotechnology, molecular boilogy, bioinformatics or biometrics were preferred, but holders of a BSc in an appropriate field, were also accepted for the training program if they were the primary researcher/breeder on their program.

\section{Survey Procedures and Selection Process}

A survey was administered to the 367 nominees with a dual purpose: 1) to assess their knowledge of basic statistical methods and 2) to select candidates with comparable levels of knowledge so as to have as uniform a group of trainees as possible. The survey was designed to determine what training they had received in the last five years, the nature of their research activities, the statistical concepts and procedures they knew and used, their computer proficiency—specifically their proficiency in Microsoft Excel (spreadsheet software) and Microsoft Access (database software), and their understanding of basic experimental design and data analysis software packages. The survey also requested general data about their country, employer, level of education and gender. They were asked to classify the activities they were engaged in, by choosing from breeding, field and lab activities, physiology, agronomy, data analysis and project management. The trainers involved in the program selected the best candidates, basing their selection on an assessment of each individual candidate.

\section{Who Was Considered a Breeder?}

Any scientist working in breeding-related fields such as evaluation of material, development of lines, management of germplasm, genetic enhancement, genetic diversity, and MB and marker-trait association studies was considered to be a breeder. More upstream areas like physiology and gene discovery were considered to be "crop improvement" rather than breeding per se. Scientists collaborating on projects with an MB component, regardless of whether or not they contributed to the genotypic data analysis, were considered as involved in MB. This differs from the definition of biotechnologists as reported on the GIPB database which excludes them from the count of breeders. Thus in this study we focused on breeders that were using biotechnology tools to achieve their breeding objectives.

\section{Scope of the Study}

This study focused on Africa and SSEA. In WCA, 13 countries where there was ongoing work on eight of GCP's target crops (bean, cassava, cowpea, groundnut, maize, rice, sorghum 
and wheat) and soybean were included in the selection process: Benin, Burkina Faso, Cameroon, Cote d'Ivoire, Democratic Republic of Congo, Ghana, Guinea, Liberia, Mali, Niger, Nigeria, Senegal and Sierra Leone. In ESA, 12 countries where there was ongoing work on all 11 targeted crops of the present study were included-Burundi, Ethiopia, Kenya, Malawi, Mauritius, Mozambique, Rwanda, South Africa, Tanzania, Uganda, Zambia and Zimbabwe. In SSEA, 11 countries with ongoing work on eight of the target crops (bean, chickpea, groundnut, maize, pigeonpea, rice, soybean, wheat) were covered-Bangladesh, China, India, Indonesia, Laos, Myanmar, Nepal, Pakistan, Philippines, Thailand and Viet Nam. In this last training group we also included a few nominees from North Africa (NA) recommended by other networks included in the nomination process. They were from three countries (Algeria, Morocco and Tunisia).

The survey was sent to all 367 nominees, with the most complete information received for 327 nominees. The response rate was highest in ESA (88.3\%), followed by SSEA and NA (81.1\%), and then WCA with the lowest response (78.9\%). Some respondents did not however complete all sections.

\section{GIPB Database}

The online GIPB database was used as an information source for the numbers of breeders and biotechnologists in each country involved in our study. The most recent information was used. In most cases this was from 2004 or 2005, but in some cases was from 2001, 2003 and 2007. The 2001 information was mostly for ESA.

\section{Results}

\section{Breeding Capacity of the National Programs}

In WCA, we collected data on 95 nominees. They were chosen based on nomination by their team, project or program member. They represented $18.7 \%$ of the total number of breeders and biotechnologists reported in the GIPB database for this region. Their level of education varied from BSc to $\mathrm{PhD}$ and included MSc and PhD students (Table 1). Most students were actually staff members serving at their national institutions, working while simultaneously pursuing their either had an MSc or were working towards a PhD. The number of MSc students was low and just one scientist only had a BSc degree. Data from the GIPB database collected during 2001-2007 indicated about $23 \%$ of the breeders were BSc level, raising the possibility that the BSc-level scientists were not nominated, had moved to other positions or were not interested in learning new technologies. More than $71 \%$ of the 95 WCA nominees were involved in MB projects (Table 2). This was high for the given sample, as compared to the GIPB database that identified only $25 \%$ of the study subjects in the same region as biotechnologists.

In ESA, 137 scientists were nominated, representing 19.6\% of the breeders and biotechnologists in the region according to the GIPB database. Their level of education spanned BSc to $\mathrm{PhD}$ (Table 1). The number of BSc holders was particularly high $(11.7 \%)$, and they were mostly in senior positions. This proportion of BSc holders was however still low compared to the $42.5 \%$ reported in the GIPB database. The high number of BSc holders nominated for training compared to WCA could be partially explained by the fact that more than half of the breeder
Table 1.

Number of nominees with highest level of education for IB-MYC training in the three regions targeted: WCA, ESA and SSEA and NA. The missing data represents nominees that completed the survey but did not fill all the fields.

\begin{tabular}{cccc}
\hline Highest degree & WCA & ESA & SSEA \& NA \\
\hline PhD & 43 & 32 & 46 \\
PhD students & 21 & 34 & 3 \\
MSc & 26 & 36 & 24 \\
MSc students & 3 & 6 & 0 \\
BSc & 1 & 16 & 9 \\
Missing data & 1 & 13 & 13 \\
\hline
\end{tabular}

Table 2.

Number of breeders involved in MB projects in the three targeted regions WCA, ESA and SSEA \& NA. The missing data represents data not filled on the survey.

\begin{tabular}{cccc}
\hline Involvement in MB & WCA & ESA & SSEA \& NA \\
\hline Yes & 66 & 79 & 69 \\
No & 24 & 51 & 25 \\
Missing data & 5 & 7 & 1 \\
\hline
\end{tabular}

population in Ethiopia and Zimbabwe are at BSc level. As a consequence the number of PhD-level breeders nominated was low (23\%). More than $50 \%$ of the nominees held an MSc or were undertaking a $\mathrm{PhD}$ program. The GIPB database showed that $37.5 \%$ of breeders in the region had an MSc degree. The higher percentage of $\mathrm{PhD}$ holders in addition to the lower percentage of MSc- and BSc-level breeders could be a sign of breeders getting more education. This is reflected in the percentage of MSc and PhD students (a total of 29.2\%). More than half $(57.7 \%)$ of the scientists were involved in MB projects (Table 2), which was very high given the $10.2 \%$ of biotechnologists reported in the GIPB database.

From SSEA and NA regions, 95 scientists were nominated. They represented $4.1 \%$ of the community of breeders and biotechnologists as reported in the GIPB database. Among the nominees that responded to the survey (86.3\%), about half (48.4\%) were $\mathrm{PhD}$ holders (Table 1). The number of $\mathrm{PhD}$ students was low (3.1\%), while $25.2 \%$ had an MSc and 9.4\% a BSc, with most of the BSc holders being from the Philippines. The GIPB database showed that in the Philippines there were many more breeders with a BSc than an MSc, and few had a $\mathrm{PhD}$. In India and Bangladesh, many breeders held an MSc. The GIPB database did not include data on India but showed that more than half of the breeders in Bangladesh (62.3\%) had an MSc. This status was well reflected in the sample of the present study. The percentage of breeders collaborating in MB projects was $72.6 \%$ (Table 2); while according to the GIPB database survey biotechnologists represented just $20.4 \%$ in the countries of our nomination, excluding data from two major players in the region: China (biotechnologist data) and India (both types of data).

\section{Gender Representation}

Female nominees were very few in Sub-Saharan Africa 
(15.8\% in WCA and $21.9 \%$ in ESA), but reached $26.3 \%$ in SSEA and NA (Table 3(a)). After the selection process the proportions were $14.8 \%$ in WCA, $18 \%$ in ESA and $33.3 \%$ in SSEA \& NA. Although selection did not include any gender-based quotas, shortlisted women candidates were given preference when making up the target number of workshop participants. Only in the SSEA and NA group was there an increase (of $7 \%$ ) in the proportion of women after selection. The proportion of trainees from SSA declined after selection by $1 \%$ and $3.9 \%$ in WCA and ESA, respectively. Countries were also assessed based on the number of female nominees. Among the countries with the highest number of nominations (17 to 41), China had the highest female representation (41.1\%) followed by Kenya (30.3\%); while Ethiopia and Mali had the lowest (15\% and $11.1 \%$, respectively) (Table $3(\mathbf{b})$ ). In the group of countries that nominated 6 to 14 scientists, Ghana and Malawi had the highest number of female nominees balance (30.7\% and $30 \%$, respectively), while Bangladesh and Senegal had the lowest $(7.7 \%$ and $7.1 \%$ women, respectively). Although there were no data to support this, the percentage of female participants per region may reflect the proportions of scientists who are women in each region; highest in SSEA and NA, followed by ESA, with the lowest proportion in WCA nominations).

\section{Data Analysis Software Proficiency}

The level of proficiency in Microsoft Access and the number of software packages used by individual respondents to analyze data were among the questions asked in the survey to help evaluate the capacity of the group to analyze scientific data. Across the three groups "low level" of proficiency in Access was $62.1 \%$ in WCA and SSEA and NA and 73\% in ESA (Table 4(a)). The difference between ESA and the other two regions much higher in ESA (40.1\%) than in WCA (27.4\%) and in SSEA and NA (25.3\%) (Table 4(b)). The ESA region had the lowest number of scientists using two different software packages (24.1\%), followed by WCA $(27.4 \%)$ and SSEA and NA (32.6\%). The latter had the smallest proportion of scientists using three software packages (11.6\%) compared to ESA (15.3\%) and WCA (16.8\%). The number of scientists dropped with each additional software package increase within the range of 4 - 8 packages. In ESA, the maximum number of software packages used was five, but reached eight in WCA and SSEA \& NA. In WCA, scientists using a high number of software packages (six and eight) were biometricians and breeders, respectively, while in SSEA and NA they were all breeders. In the latter region they were mostly $\mathrm{PhD}$ holders but some were

Table 3.

(a) Gender representation of nominees within the three regions WCA, ESA and SSEA \& NA; (b) Gender representation of nominees per country. Total represents all nominees per country.

(a)

\begin{tabular}{cccc}
\hline Gender representation & WCA & ESA & SSEA \& NA \\
\hline Males & 79 & 107 & 70 \\
Females & 15 & 29 & 25 \\
Missing data & 1 & 1 & 0 \\
\hline
\end{tabular}

(b)

\begin{tabular}{|c|c|c|c|c|c|c|c|c|}
\hline \multicolumn{3}{|c|}{ WCA } & \multicolumn{3}{|c|}{ ESA } & \multicolumn{3}{|c|}{ SSEA \& NA } \\
\hline Country list & Total & Female & Country list & Total & Female & Country list & Total & Female \\
\hline Benin & 3 & 1 & Burundi & 1 & 0 & Algeria & 2 & 2 \\
\hline Burkina Faso & 6 & 1 & D. R. Congo & 1 & 0 & Bangladesh & 13 & 1 \\
\hline Cameroon & 3 & 1 & Ethiopia & 20 & 3 & China & 17 & 7 \\
\hline Cote d'Ivoire & 5 & 0 & Kenya & 33 & 10 & India & 41 & 7 \\
\hline Ghana & 13 & 4 & Malawi & 10 & 3 & Indonesia & 2 & 0 \\
\hline Guinea & 1 & 0 & Mauritius & 1 & 1 & Laos & 1 & 0 \\
\hline Liberia & 1 & 0 & Mozambique & 12 & 2 & Morocco & 2 & 2 \\
\hline Mali & 18 & 2 & Rwanda & 1 & 0 & Myanmar & 1 & 1 \\
\hline Niger & 4 & 0 & South Africa & 5 & 1 & Nepal & 3 & 0 \\
\hline Nigeria & 26 & 5 & Tanzania & 30 & 6 & Pakistan & 1 & 0 \\
\hline Senegal & 14 & 1 & Uganda & 11 & 2 & Philippines & 8 & 2 \\
\hline \multirow[t]{3}{*}{ Sierra Leone } & 1 & 0 & Zambia & 2 & 1 & Thailand & 2 & 2 \\
\hline & & & Zimbabwe & 10 & 1 & Tunisia & 1 & 0 \\
\hline & & & & & & Viet Nam & 1 & 0 \\
\hline
\end{tabular}


Table 4.

(a) Level of proficiency in Access of the nominees in the three targeted regions; (b) Number of software packages of data analysis used by the nominees in the three regions.

(a)

\begin{tabular}{cccc}
\hline Proficiency in Access & WCA & ESA & SSEA \& NA \\
\hline Low & 59 & 100 & 59 \\
Average & 10 & 16 & 13 \\
Advanced & 3 & 2 & 2 \\
Missing data & 23 & 19 & 21 \\
\hline
\end{tabular}

(b)

\begin{tabular}{cccc}
\hline Number of software packages & WCA & ESA & SSEA \& NA \\
\hline 1 & 26 & 55 & 24 \\
2 & 26 & 33 & 31 \\
3 & 16 & 21 & 11 \\
4 & 3 & 9 & 3 \\
5 & 2 & 3 & 2 \\
6 & 1 & - & 3 \\
7 & - & - & 2 \\
8 & 1 & - & 1 \\
Missing data & 20 & 16 & 18 \\
\hline
\end{tabular}

MSc and BSc holders; in WCA they were all PhD holders. Higher levels of education seemed to be a factor in increased level of sophistication in analyzing data.

\section{Number of Activities Carried Out}

The number and the type of activities carried out by the nominees were assessed through the survey and were categorized into Agronomy, Breeding, Data analysis, Field, Lab, Physiology and Project management activities. The information was provided by $82.1 \%$ of respondents in WCA to $89.7 \%$ in ESA (Table 5(a)). In WCA, $80.8 \%$ of respondents identified breeding among their activities compared to $87.8 \%$ and $91.6 \%$ in ESA and SSEA and NA respectively. Data analysis and Field activities were the next two categories most important among the activities identified by survey participants ranging from $69.2 \%$ to $83.7 \%$ across the three regions. Physiology was the least pursued activity ranging from $19.2 \%$ to $29.6 \%$ in WCA and SSEA \& NA, respectively, compared to $26.8 \%$ in ESA. Lab activities were in the range of $53.8 \%-60.5 \%$ in the three regions. Agronomy was less counted in SSEA and NA (28.4\%) compared to $50 \%$ and $58.5 \%$ in WCA and ESA regions, respectively. Project management was less counted in WCA (26.9\%) than in ESA and SSEA and NA (49.6\% and 48.1\%, respectively). The number of activities per nominee ranged from one to all seven (Table 5(b)). In WCA most nominees had carried out 3 - 4 activities, representing 20.5\% and 30.8\%, respectively. Scientists carrying out one type of activity were $12.8 \%$, while those carrying out all seven categories were low (1.3\%). In ESA, most nominees carried out 4 - 5 categories of activities (27.6\% and $20.3 \%$, respectively). There were more nominees carrying out all seven activities than those carrying
Table 5.

(a) Type of activities carried out by the nominees in the three regions; (b) Number of activities among the seven categories carried out per nominee in the three regions.

(a)

\begin{tabular}{|c|c|c|c|}
\hline & WCA & ESA & SSEA \& NA \\
\hline Agronomy activities & 39 & 72 & 23 \\
\hline Breeding activities & 63 & 108 & 74 \\
\hline Data analysis & 54 & 100 & 66 \\
\hline Field activities & 57 & 103 & 61 \\
\hline Lab activities & 42 & 68 & 49 \\
\hline Physiology activities & 15 & 33 & 24 \\
\hline Project management & 21 & 61 & 39 \\
\hline \multirow[t]{2}{*}{ Missing data } & 17 & 14 & 14 \\
\hline & \multicolumn{3}{|l|}{ (b) } \\
\hline Number of activities & WCA & ESA & SSEA \& NA \\
\hline 1 & 10 & 8 & 5 \\
\hline 2 & 5 & 10 & 11 \\
\hline 3 & 16 & 12 & 12 \\
\hline 4 & 24 & 34 & 17 \\
\hline 5 & 12 & 25 & 21 \\
\hline 6 & 10 & 18 & 5 \\
\hline 7 & 1 & 16 & 10 \\
\hline
\end{tabular}

out only one (13\% and 6.5\%, respectively). In SSEA and NA the trend was very similar to ESA with $21 \%$ and $26 \%$ carrying out four and five activities, respectively, $12.3 \%$ all seven activities and $6.2 \%$ only one activity. In ESA and SSEA and NA where there were more BSc-level nominees, they carried out up to seven activities in ESA and six in SSEA \& NA. Comparison cannot be made with WCA as only one nominee was BSc level.

\section{Discussion}

There were more breeders at a BSc level in ESA than in the other regions. Some were senior breeders who had probably begun their career before MSc and $\mathrm{PhD}$ levels became a requirement for scientists in their respective countries. The high level of BSc holders in the African breeding community has been reported previously, although the numbers have decreased to the benefit of MSc and PhD levels between 1985 and 2001 in both WCA and ESA (Guimaraes et al., 2006). The decrease was attributed to more people pursuing higher degrees, as indicated by the fact that in 2012 most of the MSc and PhD students participating in IB-MYC training program were staff members of their national institutions. There were more nominations by institutions in ESA such as Ethiopia, Kenya and Tanzania than in WCA. In fact nomination in ESA was done at the level of the institution and not the program as in WCA. The large numbers of nominations could be related to the high number of breeders in these institutions; as reported in the GIPB database, which showed that Ethiopia had the highest number of breeders (408) followed by Kenya (63) —while 
Tanzania was not surveyed in the GIPB database. Therefore the level of capacity needed in these countries could be much larger than in countries with fewer breeders. In SSEA and NA, despite approximately half of the breeders holding a PhD degree, there were still a substantial number at the BSc level. The breeding capacity was much greater (according to the GIPB database) with an average number of breeders per million inhabitants (MI) of 3.06, ranging from .9 in Bangladesh to 9.7 in Algeria, but excluding China, India, Indonesia and Viet Nam. Breeding capacity was 2.76 breeders per MI in ESA, with the lowest capacity in Uganda (.9) and the largest in Ethiopia (5.6). WCA had the least capacity among the three regions (2.03 breeders per MI) with Mali having the highest (3.4) and Senegal the lowest (1). The higher capacity in SSEA and NA in terms of number and level of education of the breeders could explain a lesser need in capacity strengthening hence the low level of nominations for IB-MYC.

The percentage of breeders with PhDs in WCA was almost double that in ESA in both case studies (i.e. nominations for IB-MYC and the GIPB database). Our survey showed that the percentages of $\mathrm{PhD}$ students, MSc holders and MSc students were very similar in both regions. It seems that a higher level of educational attainment (PhD), by enhancing the level of technical sophistication of the breeder, has been a factor in SSA in increasing the involvement of the breeders in MB activities.

Female representation was low in our study and likely reflects the low representation of women in crop science in general. Repinski, et al. (2011) found female representation of $16.9 \%$ compared to an average of $21.3 \%$ in the present study in the three regions. In a subset of the study of Repinski et al. (2011) that reported only on people working in the private sector, female representation was even lower at one out of 27 participants in the final round of the survey (Miller et al., 2011). The low representation of women in science in general (science, technology, engineering and mathematics-STEM) is a wellknown problem not only in developing countries, but was also reported 10 years ago in industrialized countries around the world (Blickenstaff, 2005). Although updated data was not found to support this idea, it seems the level of women in science and especially in biology-related subjects and plant breeding has improved in recent years.

Level of education of users did not seem to be related to use of software packages like MS Access. For BSc through to $\mathrm{PhD}$ holders, trainees had used it, although not many considered their level of proficiency as "Advanced". In contrast, the numbers of software packages used to analyze data seemed to be more linked to the education level of trainees. Most BSc-level breeders, regardless of their region, and in some cases senior breeders, were only using one software package. A high level of sophistication in data analysis, as represented by numbers of software packages used, was dependent on level of education. Improving knowledge of statistics and experimental design is particularly important in national programs, as in most cases they do not have access to an in-house biometrician to provide guidance on experimental design before setting up experiments and on analysis after the cropping season. In WCA, for instance, due to lack of funding, most such scientific positions were eliminated or not replaced after scientists had left. As a result a disproportionately large reduction in research capacity and efficiency was experienced by many developing countries (Morris et al., 2006). Looking at the different categories of activities breeders were carrying out, more than $80 \%$ of nomi- nees in all regions were carrying out three or more activities regardless of their level of education. This shows breeders in the three regions are managing several aspects of their breeding programs to counteract the lack of adequate staff as well as the lack of specialized expertise. The BSc-level scientists carrying out project management in ESA and SSEA and NA are most probably senior breeders, as the present study showed that they existed in large numbers these two regions.

In view of the increasing complexity of skills and data that breeders need for integrated breeding, recent attempts have defined what an ideal breeding training program should look like through inputs provided by breeders from the public and private sectors in developed countries, but also the public sector in newly industrialized and developing countries (Gepts \& Hancock, 2006; Bliss, 2007; Repinski et al., 2011). The most prominent categories were practical breeding, experimental design, scientific communication, analytical aptitude, field work, statistics and data management. Some of these categories are covered in the IB-MYC training, such as breeding methodologies, experimental design, data analysis, statistics and data management. The latter is one of the major components of the IBP initiative after it was realized that there were few information systems (IS) in breeding that integrated a database of germplasm information, phenotypic data and a complete analytical pipeline (Ribaut et al., 2013). This kind of database is widely used in human disease as reviewed by (Thorisson et al., 2009). Central databases for breeding exist for each of the crops of interest for CGIAR centers. They should include pedigree information of the germplasm, phenotypic information covering several years and locations, agronomic traits they carry and in some cases related genotypic information. The centers have the responsibility to maintain, curate and populate them and they are at various stages in terms of information content. The IBP initiative is providing the cyber-infrastructure to link the large amount of available information. This will allow access to the data through query tools, and also facilitate analysis and breeding decisions via various analytical and decision support tools. The choice of the parents using all available information including pedigree, traits and performance in different environments will be a key factor in making significant progress in a breeding program (Sun et al., 2011). IB-MYC is providing trainees with the knowledge to create their own breeding databases and also integrate information provided by the crop lead center or CGIAR center responsible for their research crop. Other important training areas are statistics, experimental design and data analysis. They can have important impacts on performance prediction and breeding outcome (Sun et al., 2011). The need for statistical and related field knowledge was among the important suggestions made by scientists surveyed in the public sector of developed, newly industrialized and developing countries who generally do not have access to statistical consultants, unlike the situation in the private sector (Repinski et al., 2011).

The large number of scientists in SSEA and NA collaborating on an MB project was expected. Their countries are investing substantially in technology and research and development, and are self-reliant in most aspects of marker technologies (Ribaut et al., 2010). They are classified in Tier-1 and Tier-2, countries considered to be aware of the importance of MB, with some application of marker technologies. It was however surprising that in WCA, where most countries are classified in Tier-3 (countries struggling to sustain their breeding programs), 
the number of scientists involved in $\mathrm{MB}$ was as high as in SSEA and NA. This confirms the dramatic change reported between 1985 and 2001 in the use of biotechnology tools in that region (Guimaraes et al., 2006). During the same period, the number of biotechnologists probably increased in the USA even though the real count was available only after 2001 (Bliss, 2007). This shows that the trend in using biotechnology in agricultural sciences occurred all around the world even though the level of involvement might differ. This was facilitated by the contribution of several donors, mainly private foundations that promoted the use of technology including biotechnologies (Ribaut et al., 2008). They have contributed to promotion and use of molecular markers at different levels in Africa and Asia. The fewer breeders involved in MB reported in ESA confirmed a previous report (Guimaraes et al., 2006), although these authors also mentioned they had evidence of more biotechnology research and related development underway in ESA. From our sampling it is clear that enthusiasm for MB is still lowest in ESA-despite countries like Ethiopia, Kenya, Malawi, South Africa, Uganda and Zambia having at least half of their nominees with some level of involvement in MB. Indeed, countries like Malawi, Mozambique and Zambia that had one or no biotechnologists in 2001 are now carrying out MB projects.

It is important to establish the level of integration of $\mathrm{MB}$ in national programs, beyond the collaboration some scientists would have in MB projects with CGIAR centers and ARIs. As previously mentioned, in recent years the research objectives of the donors had driven activities in national breeding programs. If given the opportunity, would national partners be ready to carry out their own MB breeding project? The GCP as part of its mission to promote adoption of $\mathrm{MB}$ has been providing resources for high-throughput genotyping to national programs in developing countries through the Genotyping Support Services (GSS) program. Grant recipients were initially competitively selected, but in 2011 GCP made a restricted call to give the opportunity to its national partners already collaborating on $\mathrm{MB}$ projects involving international partners to carry out a small MB project alongside their bigger GCP-funded project. This was to overcome difficulties most breeders from developing countries would encounter in obtaining funding to carry out high-throughput genotyping, and to provide an opportunity to breeders exposed to MB to further extend their experience by applying the technologies to other components of their breeding program that might not capture the attention of donors. Most of the targeted breeders were managing phenotyping projects involving international teams. The genotyping was being done or coordinated by institutions they were partnering with, such as the CGIAR centers and ARIs. Projects supported by GSS needed to involve QTL identification, MAS or MABC. The partners were in SSA, except one that is based in India. However, after almost two years very few have completed their projects and some have not yet started despite several reminders and a threat to cut funding. The Indian partner was the first to complete their project while the partners from Burkina Faso, Kenya, Mali and Nigeria are at different stages. Projects from partners in Mozambique, Niger, Senegal and Tanzania seem not to have sustained the initial interest in view of the delay in submitting samples. Can this situation be explained as reluctance to apply modern breeding technologies? Probably not, as all the breeders to whom the opportunity was offered are involved in MB to a certain extent. This could be more linked to the difficulty for people to change the way they do things. In the adoption of new technologies, people's mindset and reluctance to get out of their comfort zone remain a major bottleneck anywhere in the world. Excluding Burkina Faso and Mali, all countries that had completed or advanced in their sample submission for genotyping (India, Kenya and Nigeria) are Tier-2 countries as defined (Ribaut et al., 2010). They are known to be using and applying biotechnology techniques in their breeding programs (Morris et al., 2006; Ribaut et al., 2010). Most countries that have not submitted their samples are mostly Tier-3they are developing countries with limited resources for breeding activities. The funding limitation for a prolonged period of time must have negatively impacted on the capacity of the scientists to integrate new technologies and bring them out of their comfort zone as previously described. Burkina Faso and Mali are amongst the few developing countries where transgenic crops are being tested, Bt-cotton in their case. This may explain why they are eager to use marker technologies despite being Tier-3 countries.

\section{Conclusion}

The role and activities of plant breeders are evolving rapidly. In developed countries, breeders coordinate a team where different crop improvement specialists collaborate. However, in developing countries many breeders are isolated, with limited access to specialists, and have to rely on their own knowledge and skills (Repinski et al., 2011) to overcome the shortage of complementary professionals. Historical declines in funding for agricultural research and capacity building (Morris et al., 2006), which was in part the result of the structural adjustment policies, resulted in the weakening of national programs. However, some donors are changing their strategies and are funding important programs in SSA that will make a difference. Among them, the Bill and Melinda Gates Foundation is funding major projects where CGIAR centers and ARIs are working with national programs to apply molecular markers in their breeding programs. These projects explain the high numbers of scientists involved in MB projects in SSA, especially those working on legumes (bean, chickpea, cowpea, groundnut, pigeonpea and soybean), cassava, maize and sorghum. In recent years the WB has initiated two major projects, the West Africa and the East Africa Agricultural Productivity Programs (WAAPP and EAAPP, respectively). Their goal is to stimulate and accelerate adoption of improved technologies in the top agricultural commodity priority areas of participating countries that are aligned with the top agricultural commodity priorities of the sub-region. These programs cover research, the training of breeders, and infrastructure improvement. The IB-MYC program fits perfectly with such donor efforts to improve the capacity of national programs. It is providing a knowledge update on key areas including genetics, genomics, statistics, experimental design, data management and phenotyping methodologies to enable breeders to harness the potential of MB in the near future. It aligns with updated training initiatives that were developed in the USA in recent years to enhance expertise of plant breeders such as the University of California-Davis Plant Breeding Academy (www.pba.ucdavis.edu; verified 27 Aug. 2013) that has trained breeders in the USA, Europe and Asia. In June 2013, UC-Davis launched the African Plant Breeding Academy in collaboration with the African Union's New Partnership for Africa's Development (NEPAD) initiative and the African Orphan Crops Consortium. Their training program is organized 
in six one-week sessions over two years while IB-MYC is six two-week sessions over three years. The important element in such continuous programs is the possibility to follow up with trainees and determine how they are integrating the knowledge and skills acquired in their day-to-day activities. In case they are not doing this, it is then possible to understand the difficulties they are encountering and help them to overcome them. Two more training courses should be mentioned: the "Plant Breeding for Drought Tolerance” course

(www.droughtadaptation.org; verified 27 Aug. 2013) offered by Colorado State University and the "Partnership for Research and Education in Plant Breeding and Genetics" offered by Purdue University (Miller et al., 2011). All these initiatives will enhance the capacity of breeders not only from developed countries but also developing and newly industrialized countries where the demand for highly trained skilled breeders is increasing rapidly. Challenges will however remain on how to ensure that conventional breeders in developing countries will take full advantage of the genomic era and go beyond their comfort zone by integrating marker technology and the use of more powerful statistical packages in their breeding programs to better serve the farmers in their regions. An additional challenge will be concerted action by all actors (GCP as training organizer and sponsor, regional organizations ASARECA and CORAF/WECARD, National programs) to ensure greater visibility of the SSA trainees in their institutions and regions after they have completed the course. This would enable them to benefit from additional resources (such as from EAAPP and WAAPP) to fully put into practice knowledge and skills acquired from IB-MYC to enhance their breeding programs.

\section{Acknowledgements}

The authors thank all the GCP collaborators that contributed to the design of the training program, for selecting the candidates and for designing the survey: Ibnou Dieng (Africa Rice), Theresa Fulton (Cornell University), Marcos Malosetti (Wageningen University and Research Centre, WUR), Chikelu Mba (Food and Agriculture Organization, FAO), Fred van Eeuwijk (WUR) and GCP team members Xavier Delannay, Graham McLaren, Arllet Portugal, Mark Sawkins and Hamer Paschal. We are thankful to C. Mba of GIPB for providing email contacts of the GIBP network of breeders. We are thankful to Aida Martinez of GCP for administering the survey via SurveyMonkey ${ }^{\circledR}$ and all the support she provided afterwards in extracting and compiling data from it. We appreciate the critical review and comments provided by Fred Bliss of University of California Davis. The authors thank the nominees who responded to the survey for providing us with the valuable information presented here. We thank our main donors: the Bill and Melinda Gates Foundation, the CGIAR Fund, the European Commission and the Swiss Agency for Development and Cooperation.

\section{REFERENCES}

Blickenstaff, J. C. (2005). Women and science careers: Leaky pipeline or gender filter? Gender and Education, 17, 369-386.

http://dx.doi.org/10.1080/09540250500145072

Bliss, F. A. (2007). Education and preparation of plant breeders for careers in global crop improvement. Crop Sci, 47, S-250-S-261.
http://dx.doi.org/10.2135/cropsci2007.04.0017IPBS

Delannay, X., McLaren, G., \& Ribaut, J.-M. (2012). Fostering molecular breeding in developing countries. Molecular Breeding, 29, 857873. http://dx.doi.org/10.1007/s11032-011-9611-9

Gautami, B., Foncéka, D., Pandey, M. K., Moretzsohn, M. C., Sujay, V., Qin, H. et al. (2012). An international reference consensus genetic map with 897 marker loci based on 11 mapping populations for tetraploid groundnut (Arachis hypogaea L.). PloS One, 7, e41213. http://dx.doi.org/10.1371/journal.pone.0041213

Gepts, P., \& Hancock, J. (2006). The future of plant breeding. Crop Sci, 46, 1630-1634. http://dx.doi.org/10.2135/cropsci2005-12-0497op

Guimarães, E. P., Kueneman, E., \& Paganini, M. (2007). Assessment of the national plant breeding and associated biotechnology capacity around the world. Crop Science, 47, S-262-S-273. http://dx.doi.org/10.2135/cropsci2007.04.0007IPBS

Guimaraes, E., Kueneman, E., \& Carena, M. (2006). Assessment of national plant breeding and biotechnology capacity in Africa and recommendations for future capacity building. HortScience, 41, 50 .

Miller, J. K., Repinski, S. L., Hayes, K. N., Bliss, F. A., \& Trexler, C. J. (2011). Designing graduate-level plant breeding curriculum: A delphi study of private sector stakeholder opinions. Jnrlse, 40, 82-90.

Moose, S. P., \& Mumm, R. H. (2008). Molecular plant breeding as the foundation for 21st century crop improvement. Plant Physiology, 147, 969-977. http://dx.doi.org/10.1104/pp.108.118232

Morris, M., Edmeades, G., \& Pehu, E. (2006). The global need for plant breeding capacity: What roles for the public and private sectors? HortScience, 41, 30.

Raju, N., Gnanesh, B., Lekha, P., Jayashree, B., Pande, S., Hiremath, P. et al. (2010). The first set of EST resource for gene discovery and marker development in pigeonpea (Cajanus cajan L.). BMC Plant Biology, 10, 45. http://dx.doi.org/10.1186/1471-2229-10-45

Repinski, S. L., Hayes, K. N., Miller, J. K., Trexler, C. J., \& Bliss, F. A (2011). Plant breeding graduate education: Opinions about critical knowledge, experience, and skill requirements from public and private stakeholders worldwide. Crop Science, 51, 2325-2336. http://dx.doi.org/10.2135/cropsci2011.03.0137

Ribaut, J. M., de Vicente, M. C., \& Delannay, X. (2010). Molecular breeding in developing countries: challenges and perspectives. Current Opinion in Plant Biology, 13, 213-218. http://dx.doi.org/10.1016/j.pbi.2009.12.011

Ribaut, J.-M., Delannay, X., McLaren, G., \& Okono, F. (2013). Molecular breeding molecular breeding (MB) platforms molecular breeding (MB) platforms (MBP) in world agriculture. In P. Christou, R. Savin, B. Costa-Pierce, I. Misztal, \& C. B. Whitelaw, Eds., Sustainable food production (pp. 1201-1228). New York: Springer. http://dx.doi.org/10.1007/978-1-4614-5797-8 237

Ribaut, J.-M., Monneveux, P., Glaszman, J.-C., Leung, H., Hintum, T., \& Vicente, C. (2008). International programs and the use of modern biotechnologies for crop improvement. In P. Moore, \& R. Ming, Eds., Genomics of tropical crop plants (pp. 21-61). New York: Springer. http://dx.doi.org/10.1007/978-0-387-71219-2_2

Sun, X., Peng, T., \& Mumm, R. (2011). The role and basics of computer simulation in support of critical decisions in plant breeding. Molecular Breeding, 28, 421-436. http://dx.doi.org/10.1007/s11032-011-9630-6

Thorisson, G. A., Muilu, J., \& Brookes, A. J. (2009). Genotype-phenotype databases: Challenges and solutions for the post-genomic era. Nature Reviews Genetics, 10, 9-18.

http://dx.doi.org/10.1038/nrg2483

Varshney, R. K., Glaszmann, J.-C., Leung, H., \& Ribaut, J.-M. (2010). More genomic resources for less-studied crops. Trends in Biotechnology, 28, 452-460. http://dx.doi.org/10.1016/j.tibtech.2010.06.007

Varshney, R. K., Ribaut, J.-M., Buckler, E. S., Tuberosa, R., Rafalski, J. A., \& Langridge, P. (2012). Can genomics boost productivity of orphan crops? Nature biotechnology, 30, 1172-1176. http://dx.doi.org/10.1038/nbt.2440 


\section{Abbreviations and Acronyms}

ACCI: African Centre for Crop Improvement, AFP: African Fellowship Programme, ARIs: Advanced Research Institutions,

ASARECA: Association for Strengthening Agricultural Research in Eastern and Central Africa,

CoPs: communities of practice,

CORAF/WECARD: Conseil Ouest et Centre Africain Pour la Recherche et le Développement Agricoles/West and Central African Council for Agricultural Research and Development,

DAS: Data Analysis and Statistics,

DM: Data Management,

EAAPP: East Africa Agricultural Productivity Programs,

ESA: East and Southern Africa,

GCP: Generation Challenge Programme,

GIPB: Global Partnership Initiative for Plant Breeding Capacity Building,

GSS: Genotyping Support Services,

GWS: Genome Wide Selection,

IB-MYC: Integrated Breeding Multi-Year Course,
IBP: Integrated Breeding Platform,

IBWS: Integrated Breeding Workflow System, IS: Information Systems,

MABC: Marker-Assisted Backcrossing,

MARS: Marker-Assisted Recurrent Selection, MAS: Marker-Assisted Selection,

MB: Molecular Breeding,

MI: Million Inhabitants,

MS: Microsoft,

NA: North Africa,

QTL: Quantitative Trait Loci,

SNPs: Single-Nucleotide Polymorphism,

SSA: Sub-Saharan Africa,

SSEA: South and Southeast Asia,

WAAPP: West Africa Productivity Programs,

WACCI: West African Centre for Crop Improvement, WB: World Bank,

WCA: West and Central Africa,

WUR: Wageningen University and Research Centre. 